\title{
Letters
}

Website: bmj.com

Email: letters@bmj.com

\section{Consultations do not have to be longer}

EDITOR-In our research into communication between doctors and patients, we have explored the extent to which patients' wants are met in consultations in general practice. ${ }^{1}$ On arrival at the practice, patients were asked to complete a form indicating whether they agreed or disagreed with a number of statements about what they wanted from their visit. They were subsequently asked what they felt they had got from the consultation, by using questions adapted from the patient requests form. ${ }^{2}$ Data were collected from 243 patients (86\% response) seen by 18 general practitioners at seven practices, providing a representative range of general practitioners and practice populations.

We found that patients wanted most to talk to their general practitioner. At least half also wanted to participate in decisions about treatment, wanted the doctor to listen to what they thought was wrong, have the problem and the treatment explained to them, and receive a diagnosis. Overall there was wide variation in what patients wantedsome patients wanted all 12 things we asked about, some did not want any, and half wanted between three and seven. The range of consultation time for all patients was from 2 minutes to 21 minutes. After the consultation, patients' responses again ranged from receiving none to all of the things we asked about. No patient received less than he or she had wanted.

We looked to see if there was a simple relation between the duration of the consultation and the number of things that patients wanted or received (table). Correlation between these was weak and nonsignificant, suggesting that consultations in our study were of similar length whether patients wanted (or got) almost all of the things we asked about or they wanted (or got) very few.

Although others have found that longer consultations are associated with better quality care for patients with chronic conditions and higher patient enablement

Correlation between duration of consultations in minutes and numbers of things patients wanted and got from their consultations $(n=201)$

\begin{tabular}{lcc} 
& $\begin{array}{c}\text { What patients } \\
\text { wanted }\end{array}$ & $\begin{array}{c}\text { What patients } \\
\text { got }\end{array}$ \\
\hline Pearson correlation & 0.058 & 0.091 \\
\hline$P$ value & 0.414 & 0.196 \\
\hline
\end{tabular}

scores, ${ }^{3}{ }^{4}$ our findings indicate that consultations do not have to be longer for patients to have good outcomes, and even the shortest of consultations can provide all that patients want. From the patient's perspective it seems that satisfactory consultations do not have to be long ones.

\section{Linda Jenkins research fellow}

Nicky Britten reader in medical sociology

Department of General Practice and Primary Care,

Guy's, King's College, and St Thomas's School of

Medicine, London SE11 6SP

linda.jenkins@kcl.ac.uk

Nick Barber professor of the practice of pharmacy Centre for Practice and Policy, School of Pharmacy, London WC1N 1AX

Colin P Bradley professor of general practice Department of General Practice, University College, Cork, Republic of Ireland

\section{Fiona A Stevenson lecturer}

Department of Primary Care and Population

Sciences, Roval Free and University College School of Medicine, London NW3 2PF

1 Stevenson FA, Britten N, Barber N, Bradley C. Research notes: Qualitative methods and prescribing research.J Clin Pharm Ther 2000;25:317-24.

2 Valori R, Wolshynowych M, Bellenger N, Aluvihare V, Salmon P. The patient requests form: a way of measuring Salmon $P$. The patient requests form: a way of measuring
what patients want from their general practitioner. $J$ Psychosomatic Res 1996;40:87-94.

3 Campbell SM, Hann M, Hacker J, Burns C, Oliver D, Thaper A, et al. Identifying predictors of high quality care in English general practice: observational study. $B M$ 2001;323:1-6

4 Howie JGR, Heaney DJ, Maxwell M, Walker JJ, Freeman GK, Rai H. Quality at general practice consultations: crosssectional survey. BMJ 1999;319:738-43.

\section{Patients should receive copies of letters and summaries}

EDITOR-In 2000 we attended a meeting to discuss how to improve healthcare delivery within the NHS. ${ }^{1}$ One of the recommendations was that patients, except in special circumstances, should receive copies of all letters, case summaries, or care plans written by doctors or other clinicians. We also suggested that with the patient's approval such material should be stored on a central server. The suggestion was accepted and published in the NHS Plan. The perceived advantages were threefold.

Firstly, patients have a right to know what is being written about them and, if such material is to be electronically stored, then they must be informed under the rules of the Data Protection Act and in accordance with the common law on confidentiality. An electronic health and medical record is vital if we are to develop an integrated NHS.

Secondly, to refuse to provide such information if this is the patient's wish is to deny their autonomy.

Thirdly, patients are often anonymous when they become acutely ill because their history is unknown to the doctor or clinician who sees them in primary care or when they are admitted to hospital. Access to a summary record either carried by the patient or through the electronic record, would overcome this difficulty.

The idea that patients should receive copies of letters and summaries is not new, and research has shown that it meets with high satisfaction from the patients. ${ }^{2}$ The proposal was approved by the Joint Consultants Committee subject to certain safeguards. We assumed that recommendations from the profession and the Department of Health would follow and the practice would be introduced throughout the NHS without delay

Not so. We have learnt recently that a committee set up under the NHS Modernisation Board has now recommended further research. ${ }^{3}$ Given the urgency of developing electronic medical and health records we wonder why any particular difficulties in recommending the practice nationally could not be sorted out through "action research"

\section{Advice to authors}

We prefer to receive all responses electronically, sent directly to our website. Processing your letter will be delayed unless it arrives in an electronic form.

We are now posting all direct submissions to our website within 24 hours of receipt and our intention is to post all other electronic submissions there as well. All responses will be eligible for publication in the paper journal.

Responses should be under 400 words and relate to articles published in the preceding month. They should include $\leqslant 5$ references, in the Vancouver style, including one to the BMJ article to which they relate. We welcome illustrations.

Please supply each author's current appointment and full address, and a phone or fax number or email address for the corresponding author. We ask authors to declare any competing interest. Please send a stamped addressed envelope if you would like to know whether your letter has been accepted or rejected.

Letters will be edited and may be shortened.

bmj.com

letters@bmj.com 
after introducing the policy rather than waiting until 2004.

Cyril Chantler senior associate

King's Fund, London W1G 0AN

James Johnson chairman, Joint Consultants

Committee

BMA, London WC1H 9JP

1 Hill A, ed. What's gone wrong with healthcare. London: King's Fund Publishing, London, 2000.

2 Waterston T, Lazaro C. Sending parents outpatient letters Waterston T, Lazaro C. Sending parents outpatient 1 about their children. Oual Health Care 1994;3:142-6.

3 Department of Health. Department of Health plans to Department of Health. Department of Health plans to
launch a programme of pilot projects. Copying letters to patients initiative. Invitation for proposals. www.doh.gov.uk/patientletters/proposals.htm (accessed 6 August 2002).

\section{Use of Swiss paediatric emergency department has grown}

Editor-Santos-Eggimann suggests that the increasing use of the emergency department in her Swiss hospital is mainly associated with an ageing population and immigration. ${ }^{1}$ The emergency department she analysed serves mainly adult patients. Her conclusions do not necessarily apply to children.

We recently reported the dramatic rise in the use of 10 state run paediatric casualty departments in the French speaking part of Switzerland, the region where SantosEggimann's analysis was performed. ${ }^{2}$ This increase (median 113\% (range 16-264\%) during 1990-9) is obviously not linked to a so called ageing population. Other causes have to be considered. We report here the dramatic increase in the use of our paediatric emergency department and offer an explanation for it.

Our district general hospital serves a stable population of 110000 (constant age structure and proportion of foreign nationals and refugees and practising paediatricians) about $80 \mathrm{~km}$ from the paediatric emergency department of the hospital on which Santos-Eggimann reports. Our paediatric department is the only out of hours emergency unit to care for sick children in the region.

In late 1996, because of an increasing out of hours workload from the residents (parental telephone calls and consultations), we implemented a new system to evaluate children more efficiently in our paediatric emergency department: we organised free nurse led 24 hour telephone triage, and at weekends and on bank holidays we employed local general paediatricians from the region's private practices to help assess cases.

Between 1990 and 1996 the number of annual consultations increased from 3186 to 3644 (mean rise 2.4\% a year). Between

\begin{tabular}{|c|c|c|c|c|c|c|c|c|c|c|c|}
\hline & 1990 & 1991 & 1992 & 1993 & 1994 & 1995 & 1996 & 1997 & 1998 & 1999 & 2000 \\
\hline $\begin{array}{l}\text { Patients transferred to } \\
\text { paediatric ward (\%) }\end{array}$ & NA & NA & 4.8 & 4.9 & NA & 3.9 & 5.5 & 4.2 & 3.5 & 3.1 & 3.4 \\
\hline
\end{tabular}

1996 and 2000 the number increased from 3644 to 6840 (mean annual rise $21.9 \%$ a year). We assessed the severity of emergencies by calculating from the nurses' files the proportions of patients who were transferred from the emergency department to the paediatric ward. The table shows our findings.

The gradual drop in the proportion of paediatric patients being transferred from the emergency department to the acute care inpatient department after 1996 suggests that the increased use of the emergency department was not associated with an increase in the proportion of severe cases. Our data suggest that a simple improvement in the health services for children and their families in our region led to an increasing demand in acute care out of hours.

Hospital emergency departments have to be able to respond to the population's demands. ${ }^{1}$ These, as in our case, may be triggered by hospitals' policies.

Bernard Laubscher consultant in paediatrics Hôpital Pourtalès, CH-2000 Neuchâtel, Switzerland bernard.laubscher@freesurf.ch

Cosima Donatiello registrar

Hôpital des Enfants, CH-1200 Geneva, Switzerland

1 Santos-Eggimann B. Increasing use of the emergenc department in a Swiss hospital: observational study based on measures of the severity of cases. BMJ 2002;324:1186-7. (18 May.)

2 Donatiello C, Laubscher B. "Urgent" paediatric consultations constantly increasing: a problem that affects all of French-speaking Switzerland Rev Med Suisse Romande 2001;121:305-7. (In French.)

\section{Emergency medicine}

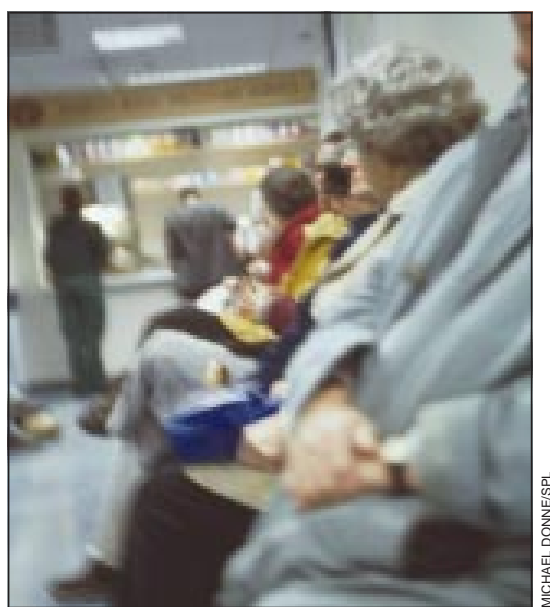

Whole system is responsible for solving overcrowding of departments

EDITOR-Fatovich highlights the important international problem of overcrowding in emergency departments, a common cause of this being the decreased availability of inpatients beds. ${ }^{1}$ The risk of waits is proportional to the average bed occupancy. In the United Kingdom it is now recognised that excessively high bed occupancy (over $85 \%{ }^{2}$ ) is a sign not of efficient management but of failure to plan

Fatovich suggests only two long term measures to address overcrowding. Although increasing the number of beds should decrease overcrowding, it has to be combined with a bed management system, working across elective and emergency components, to ensure that average bed occupancy is kept at $82-85 \%$ (this may require an extra 10000 beds in England).

Overcrowding in emergency departments can be solved only by measures across the whole health community. In the prehospital phase, systems must be in place to avoid unnecessary attendance at the emergency department (for example, easy availability of urgent primary care, protocols for ambulance services to discharge patients to a variety of destinations, access to urgent specialist clinics). Some, however, have suggested that it is better to adapt the emergency department system and that creating new routes may increase total workload. ${ }^{3}$

In the emergency department patient flows must be optimised to avoid delay (for example, by streaming of patients). Adequate staff of appropriate seniority and training must be available, staff must be used to maximum benefit (for example, by matching staffing levels and workload by the hour, autonomous practice by nurse practitioners), and diagnostics must be available at all times. Early senior input decreases unnecessary admissions.

Various community link schemes-for example, for deep vein thrombosis and chronic obstructive pulmonary diseasehave reduced numbers of patients needing a hospital bed. In the hospital, teams must ensure regular review of all patients, with processes to avoid delays in investigations and discharge. Social care and primary care must be adequately funded and designed to permit safe early discharge.

If a motorway becomes a car park at rush hour the solution is not just to add more lanes but to look at flows on and off the motorway and at the whole transport infrastructure. The principles are the same in overcrowded emergency departments and are part of the government's strategy in the United Kingdom.

Matthew Cooke Department of Health's accident and emergency adviser

University of Warwick, Coventry CV4 7AI m.w.cooke@warwick.ac.uk

1 Fatovich DM. Recent developments: Emergency medicine BMJ 2002;324:958-62. (20 April.)

2 Bagust A. Place M, Posnett JW. Dynamics of bed use in accommodating emergency admissions: stochastic simulation model. BMJ 1999;319:155-8.

3 New Zealand Health Technology Assessment Clearing House. Emergency department attendance: a critical appraisal of the literature. Christchurch: New Zealand Health Technology Assessment, 1998:35.

4 Department of Health. Reforming emergency care. London: DoH, 2001. www.doh.gov.uk/capacityplanning/reform. htm (accessed 6 Aug 2002). 


\section{Changes to algorithm were not approved} by Resuscitation Council (UK)

EDITOR-We are concerned about the resuscitation algorithm displayed in Fatovich's review on emergency medicine. ${ }^{1}$ The legend below the algorithm indicates that it was adapted from the Resuscitation Council (UK) website. We wish to make it very clear that these modifications are not consistent with the Resuscitation Council (UK) and European Resuscitation Council (ERC) guidelines for advanced life support (ALS), and the changes to the algorithm were made without approval by either of these organisations. The publication of this modified algorithm in a prominent British journal will confuse European healthcare professionals and detracts from the consistent educational approach we strive to achieve on the Resuscitation Council (UK) and European Resuscitation Council course I advanced life support.

The algorithm displayed in Fatovich's review is the one published in the International Guidelines 2000 for Cardiopulmonary Resuscitation and Emergency Cardiovascular Care. ${ }^{2}$ The correct European Resuscitation Council and Resuscitation Council (UK) universal algorithm for advanced life support is displayed at www.resus.org.uk/ pages/alsalgo.pdf. Vasopressin is not included in the European Resuscitation Council and Resuscitation Council (UK) guidelines. ${ }^{3}$ This decision was made by the advanced life support working group of the European Resuscitation Council after careful consideration of the scientific evidence and economic consequences of including vasopressin in the guidelines. A recent randomised controlled trial showing no benefit from vasopressin after cardiac arrest in hospital provides further support for this decision. ${ }^{4}$ The results of a European multicentre prospective randomised trial comparing vasopressin with adrenaline in prehospital cardiac arrest will be available soon (V Wenzel, personal communication). Any role for vasopressin in the European Resuscitation Council and Resuscitation Council (UK) guidelines for advanced life support will be reconsidered at this stage.

Other adaptations to the algorithm include changes to the list of potentially reversible causes and to the wording of the interventions to be considered during cardiopulmonary resuscitation.

Jerry P Nolan consultant in anaesthesia and intensive care medicine

Royal United Hospital, Bath BA1 3NG

jerry.nolan@ukgateway.net

David Gabbott chairman, Advanced Life Support

Course Subcommittee

Sarah Mitchell director

Robert Bingham chairman

Resuscitation Council, London WC1H 9JR

1 Fatovich DM. Recent developments: Emergency medicine BMJ 2002;324:958-62. (20 April.)

2 American Heart Association in collaboration with the International Liaison Committee on Resuscitation (ILCOR). International guidelines 2000 for cardiopulmonary resuscitation and emergency cardiovascula monary resuscitation and emergency cardiovascula 3 Care a consensus on science. Resuscitation 2000;46:1-448. Latore F, Nolan J, Robertson C, Chamberlain D, 2000 for adult advanced life support. A statement from the advanced life support working group and approved by the executive committee of the European Resuscitation Council. Resuscitation 2001;48:211-21.

4 Stiell IG, Hebert PC, Wells GA, Vandemheen KL, Tang AS, Higginson LA, et al. Vasopressin versus epinephrine for inhospital cardiac arrest: a randomised controlled trial. Lancet 2001;358:105-9.

\section{Ambulatory alternatives exist}

EDITOR-Fatovich's clinical review of emergency medicine does not address several initiatives to resolve the situation of inappropriate referral and access block. ${ }^{1}$ The author has suggested expanding existing systems, such as increasing the number of beds and enlarging emergency departments, which may only partially relieve the problem.

Several other strategies to improve the situation have undergone trials in south west Sydney, Australia. These systems work as complementary services to the emergency department and are based on improving communication with general practitioners and other healthcare workers and providing a range of alternative paths for patients with acute conditions.

These strategies include a general practice run after hours on the hospital site, with experienced general practitioners working on a rota system every evening, and direct referral from general practitioners or the emergency department to an ambulatory care service with a specialist on cal seven days (24 hours) a week. ${ }^{2}$ Patients may be referred to these services and offered an alternative to hospital admission. A responsive primary health nursing service is also available to target patients attending emergency departments who are at risk of presenting again.

This approach, involving multidisciplinary and multifaceted community care, improved communication between the general practitioner and hospital, and integration with the emergency department, provides many care options. It also results in better use of the emergency department's stretched resources.

Stephen F Wilson director, ambulatory car Nicholas Collins staff specialist, ambulatory care Macarthur Health Service, PO Box 149, Campbelltown, New South Wales 2560, Australia stephen.wilson@swsahs.nsw.gov.au

1 Fatovich DM. Recent developments: Emergency medicine. BMJ 2002;324:958-62. (20 April.)

2 Wison S, Chapman C, Nancarrow L, Collins J. Macarthur model for ambulatory services. Aust Health Review 2001;24:187-93.

\section{Author's reply}

EDITOR-Cooke reinforces the international nature of the problem of emergency department overcrowding. I support the comment by Cooke, that excessively high bed occupancy (over 85\%) is not a sign of efficient management but a sign of failure to plan. Derlet has said that, should there be a major epidemic of infectious disease or national catastrophe, emergency departments and hospitals could not accommodate the demand.

Cooke is correct in saying that the solutions require a response of the whole system but incorrect in saying that I suggested only two long term measures to address overcrowding. The text clearly states that all the causes of overcrowding outlined in box 1 need to be addressed. As said in the methods, because of space restrictions it is simply not possible to provide a comprehensive review.

Cooke also says that an extra 10000 beds are required in England to help decrease overcrowding, with the aim of keeping bed occupancy at $82-85 \%$. This reinforces the finding that overcrowding in emergency departments is due to increased demand and decreased capacity. ${ }^{1}$ The data from Poolman et al on the prolonged times required for organising admission of patients highlight the congestion of the acute hospital system. They also reinforce the loss of clinical productivity and effectiveness for doctors participating in disposing patients. ${ }^{2}$

Wilson suggests several strategies, including a general practice after hours on the hospital site. This sends a clear message to the community to attend the hospital with their problem, thus potentially aggravating the situation. The focus should be to use community based resources as much as possible.

I agree with the comments of Nolan et al. The reference for the algorithm came from reference 6 in the paper, and this is what was originally submitted. The reference to the Resuscitation Council (UK) website was an editorial mistake. The adaptations reflect the American Heart Association algorithm. ${ }^{3}$ I agree with their comments on vasopressin, and the reference they quote to support this is the same as reference 7 in my paper. Although I do not use vasopressin in my practice, the comments in my paper that vasopressin is included as an option in the (American Heart Association) algorithm nevertheless reflects that algorithm.

Daniel M Fatovich specialist in emergency medicine Royal Perth Hospital, Perth, Western Australia 6000 , Australia

daniel.fatovich@health.wa.gov.au

1 Derlet RW. Overcrowding in emergency departments: increased demand and decreased capacity. Ann Emerg Med 2002:39:430-2.

2 Poolman RW, Hulscher JBF, Noten HJ, Steller EP. Bed-blockers. bmj.com 2002. bmj.com/cgi/eletters/324 7343/958\#21581 (accessed 6 August 2002).

3 International Guidelines 2000 Conference on Cardiopulmonary Resuscitation and Emergency Cardiovascular Care. Circulation 2000;102(suppl 1):1-384

\section{GPs mustn't be dismayed about grasp of cognitive therapy}

EDITOR-No one should be surprised when a brief training in cognitive therapy proves ineffective in improving a patient's anxiety or depression after six months. ${ }^{1}$ As a psychologist, I have taught cognitive therapy interventions in courses for graduate students, psychiatry residents, and primary care doctors. I recognise that none of these courses results in a skill base that can be implemented immediately to improve patients' outcome.

Graduate students need several years of internships to become effective cognitive therapists. Psychiatry residents have difficulty integrating this model into their 
paradigm, whether that be psychopharmacological or psychodynamic. The most that can be expected from primary care doctors, given the amount of training they receive and the amount of time they have to interact with patients, is much less than the authors hoped for.

A more reasonable goal would be to educate primary care doctors in four aspects of cognitive therapy. They should recognise the signs and symptoms of depression and its various subtypes, as well as what is not depression but normal bereavement or adjustment; learn how to communicate effectively with patients to educate and encourage them about the illness; treat with an antidepressant when indicated; and learn how to make effective referrals. The last recommendation is important, since combination treatment is more effective than either alone.

James L Spira staff psychologist

Health Psychology Program-Mental Health Services, Navy Medical Center, San Diego, CA 92134, USA

JimSpira@aol.com

1 King M, Davidson O, Taylor F, Haines A, Sharp D, Turner R. Effectiveness of teaching general practitioners skills in brief cognitive behaviour therapy to treat patients with depression: randomised controlled trial. $B M J$ 2002;324:947-50. (20 April.)

\section{Bread is fortified with folic acid in Hungary}

EDITOR-The European governments were criticised by Oakley for failing to mandate the universal fortification of flour with folic acid, a public health action that can prevent neural tube defects and other congenital abnormalities in fetuses, as well as cardiovascular disorders in adults, including elderly people. ${ }^{12}$ However, we would like to remind Oakley and the readers of the $B M J$ that a bread fortification programme was launched in Hungary in August 1998. ${ }^{3}$ This public health project had three differences from the flour fortification initiative in the United States.

Firstly, bread was fortified because it is the national basic food, average daily intake being $200 \mathrm{~g}$. The consumption of bread can generally be measured or estimated much more easily than that of flour, and our pilot study showed that quality control in Hungarian mills could not be guaranteed. Fortified bread could be produced by adding yeast fortified with vitamins to bread dough. Flour is $75 \%$ of Hungarian bread and $20 \%$ of vitamins are lost during production.

Secondly, we fortified bread with three B vitamins. Fortification with $330 \mu \mathrm{g}$ folic acid would mean that $1-2 \%$ of the Hungarian population would exceed the tolerable upper intake of folic acid for healthy people $(1000 \mu \mathrm{g}){ }^{4}{ }^{4}$ Vitamin B12 is an independent risk factor for neural tube defects and may be useful in neutralising the possible adverse effect of high doses of folic acid in patients with pernicious anaemia. However, only $1-3 \%$ of oral vitamin B12 can be absorbed via non-physiological mass action, thus it is necessary to use a high dose $(25 \mu \mathrm{g})$ of vitamin B12. Vitamin B12 has no toxic effect under $1000 \mu \mathrm{g}$. Vitamin B6 is also important in preventing homocysteine related vascular diseases.

Thirdly, the Hungarian bread fortification programme was not compulsory because consumers should be able to decide whether they want to buy fortified bread.

The Hungarian project had a good start but there was no official support. With the election of a new government this year, bread fortification has become among the highest priorities of the public health programme. This commitment is exemplified by the fact that one of us (MK) is state secretary in the government.

\section{Andrew E Czeizel doctor}

Foundation for the Community Control of Hereditary Diseases, Budapest 1148, Hungary

Mihály Kökény state secretary

Health and Social Ministry, Budapest 1051

1 Oakley GP. Delaying folic acid fortification of flour. $B M J$ 2002;324: 348-9. (8 June)

2 Czeizel AE. Prevention of congenital abnormalities by periconceptional multivitamin supplementation. $B M$ 1993;306:1645-8

3 Czeizel AE, Merhala Z. Bread fortification with folic acid, vitamin B12, and vitamin B6 in Hungary. Lance $1998 ; 352: 1225$

4 US National Academy of Sciences. Dietary reference intakes: folate, other $B$ vitamins and choline. Washington, DC: National Academy Press, 1998.

\section{Authors respond to criticism of rheumatoid arthritis twin study}

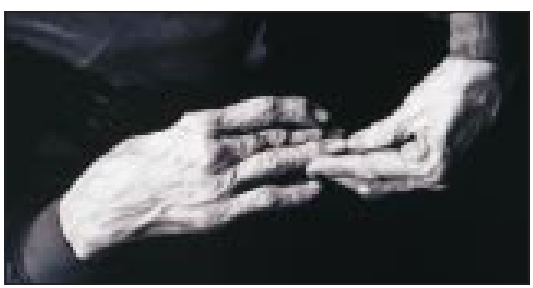

EDITOR-The letter by MacGregor et al in response to our twin study focuses on three points: heritability, bias, and the contribution of specific genes to the aetiology of rheumatoid arthritis.

MacGregor et al state that two previous twin studies on rheumatoid arthritis have reported comparable heritability estimates at approximately $60 \%$. But a heritability estimate is a theoretical concept relying on several assumptions which cannot at present be met in rheumatoid arthritis. Besides, heritability estimates are population specific since the variation of environmental and genetic effects may not be identical in different geographical areas and ethnic populations.

In our study, twins younger than 42 were $92 \%$ of the total population, but an age adjusted estimate accords well with the latest population based study from Norway in which the prevalence of rheumatoid arthritis between 20 and 79 years was 0.437. Prevalences exceeding $1 \%$ were found only in people older than 60. Macgregor et al state that the concordance estimate of zero is by definition biased since monozygotic concordance pairs do exist. But bias is a systematic error originating from inherent problems including selection, information, and confounding. In our study all possible measures were taken to minimise bias-for example, by contacting all available people in the entire Danish twin population irrespective of disease status, by using multiple sources of information and by doing specialist examination of all candidate probands.

Furthermore, whether concordant pairs exist in excess of coincidence is questionable. In the study by Silman et al 19 monozygotic and 39 dizygotic twin pairs would be anticipated to be concordant by chance. ${ }^{3}$ This study, however, identified only 14 monozygotic and four dizygotic concordant pairsthat is, there were no concordant monozygotic pairs in excess of what would be expected by chance. Therefore, we cannot accept the inference that our study is biased by definition because we failed to identify concordant monozygotic pairs, given that the literature on twin methodology points to the risk of bias towards overascertainment of monozygotic pairs, and concordant monozygotic pairs in particular.

MacGregor et al argue that the genetic variation in HLA in rheumatoid arthritis and the recent identification of genetic regions linked to the disease is evidence of an aetiological contribution from specific genes. The finding of several possible genetic risk factors is interesting but their definite significance still remains to be settled, just as for the bulk of putative environmental effectors proposed so far. ${ }^{5}$ Experience from diabetes, which has a much larger genetic contribution in twin studies, suggests that this will be a tedious process.

Anders Svendsen consultant

Department of Rheumatology, Odense University Hospital, 5000 Odense C, Denmark

Niels V Holm associate professor

Department of Radiotherapy and Clinical Oncology, Odense University Hospital

Kirsten Kyvik associate professor

Danish Twin Registry, Department of Public

Health, Epidemiology, University of Southern Denmark, Odense

Per Hyltoft Petersen master of science

Department of Clinical Chemistry, Odense University Hospital

Peter Junker professor

Department of Rheumatology, Odense University Hospital

1 MacGregor AJ, Lanchbury J, Rigby AS, Kaprio J, Snieder H. Using twin studies to label disease as genetic or environmental is inappropriate. BMJ 2002;324:1100. (4 May.)

2 Kvien TK, Glennas A, Knudsrod OG, Smedstad LM, Mowinckel $\mathrm{P}$ Forre $\mathrm{O}$. The prevalence and severity of rheumid a toid arthitis in Oslo. Results from a county register and 1997;26:412-8

3 Silman AJ, MacGregor AJ, Thomson W, Holligan S, Carthy D, Farhan A, et al. Twin concordance rates for rheumatoid arthritis: results from a nationwide study. Br J Rheumatol 1993;32:903-7.

4 Lykken DT, Tellegen A, DeRubeis R. Volunteer bias in twin research: the rule of two-thirds. Soc Biol 1978; 25:1-9.

5 Silman AJ, Hochberg MC. Epidemiology of the rheumatic diseases. New York: Oxford University Press, 1993. 


\section{Grading referrals to specialist breast units}

\section{Guidance on referral needs to be evidence based}

EDITOR-We were surprised at the amount of media interest in the data given by Thrush et al in their letter on grading referrals to a specialist breast unit. ${ }^{1}$ We have two main concerns. Firstly, the data presented do not support their conclusions. Secondly, the issue is not simply about the inappropriateness of general practitioners to determine urgency, but more about the development of evidence based guidance and general practitioners' adherence to this guidance.

The authors say that the two week wait initiative is not ensuring that most patients with symptomatic cancer are seen within two weeks of referral. This is not supported by the data presented in that over half of patients $(56 \%)$ found to have breast cancer were in fact referred as urgent cases. No data are presented concerning delays experienced by the non-urgent group. Their data show that $9.3 \%$ of urgent referrals were diagnosed with cancer compared with 1.7\% of non-urgent referrals. This equates to a diagnosis of cancer being six times more likely in urgent compared with non-urgent referrals. Hence it may be valid to conclude that general practitioners' use of the guidance is working to some extent

Thrush et al do not differentiate according to whether patients fulfilled the urgent referral criteria; this makes it impossible to distinguish between the effectiveness of the guidance and the adherence of general practitioners to the guidance. It is well established that the two week referral guidance overall lacks an evidence base, especially as there is a lack of good quality data on the predictive value of symptoms. ${ }^{2}$

Longer delays for breast cancer patients have been found to be associated with worse survival rates. ${ }^{3}$ However, the delay between referral by the general practitioner and first appointment in secondary care is only one component of the total diagnostic delay. Evidence is lacking on the association of individual components of delay (patient delay, primary care delay, and secondary care delays) with stage at diagnosis and survival.

High quality research is clearly needed to investigate diagnostic delay and clinical outcome to produce evidence based referral guidance and develop effective strategies to ensure that such guidance is adhered to.

Victoria L Allgar senior research fellow in primary care oncology

Richard D Neal Macmillan senior lecturer in primary care oncology

Centre for Research in Primary Care, University of Leeds, Nuffield Institute for Health, Leeds LS2 9PL v.l.allgar@leeds.ac.uk

Shane W Pascoe research fellow

Meanwood Group Practice, Leeds LS6 4JN

Thrush S, Sayer G, Scott-Coombes D, Roberts JV. Grading referrals to specialist breast unit may be ineffective. $B M$ J 2002;324:1279. (25 May.)
2 Jones R, Rubin G, Hungin P. Is the two week rule for cancer referrals working? BMJ 2001;322:1555-6. 3 Richards MA, Westcombe AM, Love SB, Littlejohns P, Ramirez AJ. Influence of delay on survival in patients with breast cancer: a systematic review. Lancet 1999;353:1119-26.

\section{Communication has been degraded to exchange of dataset}

EDitor-The contents of Thrush et al's letter will come as no surprise to general practitioners, who are well aware of the difficulties in selecting patients for the two week wait. ${ }^{1}$ As long ago as 2000 at the conference of local medical committees general practitioners supported my motion criticising the policy for being politically inspired and being unlikely to improve the overall care for patients with cancer.

All a general practitioner can do is sort symptomatic patients into two groupsthose more likely and those less likely to have cancer. It is inevitable that, wherever the line is drawn, patients will be incorrectly sorted, and the real worry is that the two week wait requirements result in an increased time for those unfortunate to have cancer without typical signs.

In such cases the patient has to deal not only with the diagnosis of cancer but also with the knowledge that she waited a longer time than ideal for assessment. The relationship between the general practitioner and the patient can only suffer, and I am sure I am not the only general practitioner to have received a complaint because a patient referred exactly within guidelines unexpectedly had a malignancy.

The tick box referral forms favoured by breast units have degraded communication between general practitioners and consultants to the level of a transfer of a basic dataset, and so the opportunity for an alert consultant to expedite a routine referral on clinical grounds is missed Perhaps there should be a reassessment of the role of professionals within the referral process, with consultants taking responsibility for reading letters on receipt, and assigning waiting times, and general practitioners in return providing a narrative style letter containing adequate information to allow the consultant to perform this task. Come to think of it, wasn't that what we used to do?

Andrew M Green general practitioner

Hedon, East Yorkshire HU12 8JD

andrew@burstwick.plus.com

1 Thrush S, Sayer G, Scott-Coombes D, Roberts JV. Grading referrals to specialist breast unit may be ineffective. $B M J$ 2002;324:1279. (25 May.)

\section{General perception of stroke}

\section{Knowledge of stroke is lacking}

EDITOR-Yoon and Byles found that the recognition of symptoms of stroke and risk factors for it was poor. ${ }^{1}$ Lack of knowledge results in delays in seeking medical care. ${ }^{2}$ As a result, patients with stroke may fail to gain the benefits of acute treatments-for exam- ple, acute thrombolysis-because of the narrow therapeutic window. ${ }^{3}$

We conducted a large prospective questionnaire study among elderly patients attending a UK hospital clinic. ${ }^{4}$ Patients with established risk factors for stroke (atrial fibrillation, diabetes, hypertension, previous stroke, transient ischaemic attack) were interviewed. A total of 410 patients (mean age 78 ) gave their responses to a semistructured questionnaire.

Altogether 336 patients could identify the symptoms of stroke correctly; the remainder were not sure or gave incorrect answers. Forty one thought that stroke is caused by damage to the heart, and 353 correctly correlated stroke with brain damage. On free recall, 267 correctly identified at least one established risk factor for stroke; the rest did not know any. The commonest perceived risk factor was stress (reported by 213 ) and the second commonest was hypertension $(\mathrm{n}=197)$.

When patients were asked to choose risk factors for stroke (on a questionnaire with closed questions containing both correct and incorrect responses) stress was again identified as the commonest factor (by 254 patients). Many subjects reported other incorrect risk factors-for example, liver disease, cold, no rest. Only 62 patients considered themselves to be at increased risk of stroke because of underlying disease. Few subjects $(n=90)$ had been informed by a health professional that their underlying condition predisposed them to stroke.

Our results show that understanding about symptoms of stroke, risk factors, perceived risk, and organ affected was incomplete among a population at risk. We agree with Yoon and Byles that educational strategies are needed to correct misconceptions and to enable patients to seek medical help and early treatments for stroke. Effective educational programmes could also increase public awareness of stroke.

Abhaya Gupta specialist registrar on geriatric medicine Llandough Hospital, Cardiff CF64 2XX guptaabhaya@hotmail.com

Peter Thomas consultant physician

Prince Philip Hospital, Llanelli SA14 8QF

1 Yoon SS, Byles J. Perception of stroke in the general public and patients with stroke: a questionnaire study. $B M J$ 2002;324:1065. (4 May.)

2 Williams LS, Bruno A, Rouch D, Marriott DJ. Stroke patients' knowledge of stroke: influence on time to presenpatien Stroke 1997;28:912-5.

3 National Institute of Neurogical Disorders and Stroke Nations Stroke

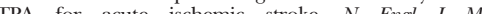

4 Gupta A, Thomas P. Knowledge of stroke among elderly patients at increased risk of stroke. J Am Geriatrics So 2000;48:S76. (Abstract)

5 Panicoli AM, Broderick J, Kothari R, Brott T, Tuchfarber A, Miller R, et al. Public perception of stroke warning signs and knowledge of potential risk factors. JAMA 1998;279:1288-92.

Poor knowledge of stroke can be improved by simple measures

Editor-Yoon and Byles's paper highlights the need for greater public education regarding recognition of risk factors and symptoms of stroke. ${ }^{1}$ In an audit of patients' 
and carers' knowledge of stroke we surveyed 39 patients with recent cerebral infarction without cognitive or language difficulties and 16 carers. ${ }^{2}$ Only 14 of the patients and 10 of the carers recognised the onset of stroke, and when presented with some common scenarios a third did not recognise half the common presenting symptoms of stroke (hemiparesis, hemisensory loss, dysphasia, homonymous hemianopia, etc).

When asked about risk factors for cerebral infarction the 55 people interviewed could only name 1.5 risk factors on average; 17 could not name any. After an information booklet on stroke was provided they could name 2.5 risk factors on average, and only nine could not identify any. Thirty six of the participants read the booklet.

Our audit suggests that most patients and many carers do not recognise the onset of stroke and that knowledge of risk factors is poor. Knowledge improved, however, with the provision of a simple information booklet, which most people read.

D $\mathbf{R}$ Collins specialist registrar in geriatric medicine Leeds General Infirmary, Leeds LS1 3EX collinsronan@yahoo.co.uk

P M E McCormack consultant physician in geriatric medicine

James Connolly Memorial Hospital,

Blanchardstown, Dublin 15, Republic of Ireland

D O'Neill professor of geriatric medicine

Adelaide and Meath Hospital, Tallaght, Dublin 24

1 Yoon SS, Byles J. Perceptions of stroke in the general public and patients with stroke: a qualitative study. $B M$ 2002;324:1065-8. (4 May.)

2 Collins DR, O'Neill D, McCormack PME. Patient and carer knowledge of symptoms and risk factors in stroke. Age Aging 1999;28(suppl 1):53.

\section{Licensing system for doctors}

\section{Licensing seems inevitable, but is it necessary?}

EDITOR-I'm sure that the revalidation of doctors in the United Kingdom that Eaton mentions in her news article will proceed. ${ }^{1}$ This will be mainly because it is driven by politicians and academics, and because, like so many of these things, it seemed like a good idea at the time, but I challenge whether it will make any difference to overall quality of service or care.

We have had this in Australia for 10 years now, yet there is still little hard evidence that it has done anything but introduce yet another layer of bureaucracy. We call it vocational registration (VR), and we have to accumulate a minimum number of points over a triennium. For me it has changed nothing in my work habits, as I always enjoyed doing continuing medical education when I chose those things I most felt I needed to brush up in. Now, the compulsion has removed a lot of the fun of this while no doubt providing a lot of "gainful employment" to the "specialists" retained by the drug companies to lecture, they being only too happy to "sponsor" the meetings because of the great access this gives then to the doctors. The fact that this automatically narrows the scope of subjects to those relevant to the latest (and most expensive) drugs seems bye the bye-you will find the "authorities" remarkably reluctant to put up real money to provide this education, once they have put the requirement in place.

I am convinced one's conscientiousness in keeping up to date is far more a function of one's basic personality, which is decided well before college, let alone medical school, and people who are lazy will still find ways to be so, and people (the vast majority) who are not will just have to jump through all the loops and hoops. Have fun, people-never learn from others' mistakes.

Peter R Bradley general practitioner Brisbane, Queensland 4127, Australia pbradley@bigpond.com.au

1 Eaton L. Government proposes licensing system for doctors. BMJ 2002;324:1235. (25 May.)

\section{Accumulating points has not changed the} way I learn

Editor-With reference to the article by Eaton, I agree with Bradley (above), a fellow sufferer of MOPSITIS. ${ }^{1}$ As a thoracic physician, the accumulation of points for maintenance of professional standards (MOPS) for the Royal Australian and new Zealand College of Psychiatrists has been a waste of time and has not changed the way $I$ learn (I avoid drug company lectures). It also does not adequately acknowledge the varied and complex ways in which the grey matter has been learning since the late cretaceous period.

I find conferences in general a waste of time, enjoy using my computer (now, cyber lectures), researching and writing papers, and reading journals. The system cannot keep up with cyber learning, and it is impossible so far to keep a points record of this activity, which occurs all day long in the office through access to the wide range of state of the art therapeutics and other information that can be accessed as a problem arises.

Only a miniscule number of points are credited for the writing of a paper, which could take hundreds of hours, but a few days by the pool at a conference clocks up lots. As for trying to do quality assurance activities and get points for ethics in private practice, my mind boggles at which planet these college bureaucrats live on. Regardless, I plod on, hoping that it will all go away. One year I amassed enough points for five years, but undaunted, I kept on learning.

Ironically, our college leaders, well behind the front lines, preside over antediluvian websites of little use for cyber education or easy access to peers for advice (like generals from the first world war?). As for such innovations as rapid responses, I am sure I will be dead by the time the Internal Medicine Journal or the Medical Journal of Australia has these. It could just weaken the hegemony of their editors.

Roger K A Allen consultant thoracic and sleep physician

Private Practice, Suite 299, St Andrew's Place, 39 North St, Spring Hill, Brisbane, Queensland 4000 Australia

rogerallen@ozemail.com.au
1 Eaton L. Government proposes licensing system for doctors. BMJ 2002;324:1235. (25 May.)

\section{Corrections}

Psychological stress and cardiovascular disease

We apologise for a technical error that resulted in the omission of the names and addresses of the first five authors of the authors' reply to this cluster of letters (10 August, p 337). The authors should have been published as follows.

John Macleod clinical research fellow

Department of Primary Care and General Practice, University of Birmingham, Birmingham B15 2TT

George Davey Smith professor of clinical epidemiology Department of Social Medicine, University of Bristol, Bristol BS8 2PR

Pauline Heslop research assistant Nora Fry Research Centre, University of Bristol, Bristol BS8 1TX

Chris Metcalfe research assistant

MRC Biostatistics Unit, University of Cambridge, Cambridge CB2 2SR

Douglas Carroll professor of applied psychology School of Sport and Exercise Science, University of Birmingham, Birmingham B15 2TT

Carole Hart research fellow

Department of Public Health, University of Glasgow, Glasgow G12 8RZ

We also apologise for errors in the citation of references in this letter. The reference list is correct, but the data in the table from the Whitehall II study are abstracted from references 1 and 5 [not references 1 and 3 as published]. In the text, validation of the Reeder stress inventory is described in reference 3 [not reference 4 as published in the third paragraph] and experimental evidence of the relation between depression and coronary mortality is reported in reference 4 [not reference 5 as published in the fourth paragraph]. The other citations of references are correct.

Off label prescribing in children

We apologise for a technical error that resulted in the omission of the names and addresses of the first two authors of the first letter in this cluster of two letters (10 August, p 338). The authors should have been published as follows.

David G Bartle senior house officer paediatrics Royal United Hospital Bath, Bath BA1 3NG dbartle1@hotmail.com

F O Finlay consultant paediatrician in community child health

Child Health Department, Banes Primary Care Trust, Bath BA1 3QE

S Guiton veterinary surgeon

12 Ruby Place, Bath BA2 4EH

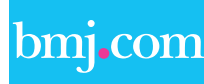

Rapid responses

Correspondence submitted electronically

is available on our website 